\title{
Histochemical and immunohistochemical profile of human and rat ocular medial rectus muscles
}

\author{
Branka Stirn Kranjc • Vika Smerdu • Ida Eržen
}

Received: 14 April 2009 / Accepted: 15 June 2009 / Published online: 17 July 2009

(C) The Author(s)2009. This article is published with open access at Springerlink.com

\begin{abstract}
Purpose To compare the organization of human and rat ocular medial recti muscles (MR).

Methods The cryosections of human and rat MR were processed for myofibrillar ATPase (mATPase), succinate dehydrogenase and glycerol-3-phosphate dehydrogenase. To reveal myosin heavy chain (MyHC) isoforms, specific monoclonal antibodies against MyHC- $1 / \beta$ - slow, $\alpha$-cardiac $(-\alpha),-2 \mathrm{a},-2 \mathrm{x},-2 \mathrm{~b},-$ extraocular (eom), -embryonic (-emb) and -neonatal (-neo) were applied. The MyHC gene expression was studied by in situ hybridization in human muscle.

Results The muscle fibers were arranged in two distinct layers in both species. In the orbital layer most fibers were highly oxidative and expressed fast MyHC isoforms, whereas slow and oxidative fibers expressed MyHC-1 and $-\alpha$, some of them also MyHC-2a, $-2 \mathrm{x}$, -eom, very rarely -emb, and - neo. In the global layer, slow fibers with very low oxidative and glycolytic activity and three types of fast fibers, glycolytic, oxidative and oxidative-glycolytic, could be distinguished. The slow medium-sized fibers with
\end{abstract}

Financial relationship: none

The authors have full control of all primary data and agree to be reviewed upon request

\footnotetext{
V. Smerdu $\cdot$ I. Eržen

Institute of Anatomy, Faculty of Medicine,

University of Ljubljana,

Korytkova 2,

1000 Ljubljana, Slovenia

B. Stirn Kranjc $(\bowtie)$

University Medical Centre, University Eye Hospital Ljubljana,

Grabloviceva 46,

1000 Ljubljana, Slovenia

e-mail: Branka.Stirn@guest.arnes.si
}

mATPase activity stable at $\mathrm{pH} 4.4$ expressed mostly MyHC-1 and $-\alpha$ in rat, while in humans they coexpressed MyHC-1 with $-2 \mathrm{~b},-2 \mathrm{x}$, -eom, and -neo. In both species, the fast fibers showed variable mATPase activity after preincubation at $\mathrm{pH} 9.4$, and co-expressed various combinations of MyHC-2b, -2x, $-2 \mathrm{a}$ and -eom but not -emb and -neo. MyHC-2b expressing fibers were larger and glycolytic, while MyHC-2a expressing fibers were smaller and highly oxidative in both species. To our knowledge, the present study is the first that demonstrated the expression of MyHC-2b in any of human skeletal muscles. Though the expression of MyHC genes did not correlate with the immunohistochemical profile of fibers in human MR, the expression of MyHC-2b gene was undoubtedly confirmed. Conclusions Rat MR represent a good model that can be applied to study human MR in experiment or disease, however certain differences are to be expected due to specific oculomotor demands in humans.

Keywords Ocular medial rectus muscle · Rat · Human · Histochemistry · Immunohistochemistry .

Myosin heavy chain isoforms $\cdot$ In situ hybridization

\section{Introduction}

The extraocular muscles (EOM) are unique in their structure and function. The extraordinary functional demands including globe rotation, imposed upon these muscles made them the fastest and the most fatigue resistant skeletal muscles [10]. Compared to other skeletal muscles they are not respecting the traditional fiber type classification schemes. EOM differ in their histochemical profile, type of innervation and fiber type distribution [48, 51].The sequential development of EOM fiber types is 
believed to be conserved across the mammalian species, but may follow a different sequence in frontal and lateral-eyed species [36]. In rodents, the composition of EOM is in principle similar to that of other mammals, including humans, however species differences were reported and mostly concern muscle fiber type characteristics [16].

Several attempts at classification of fiber types in EOM of different mammals, i.e. rodents, monkeys, cats, sheep, rabbits and humans have been made by studying the morphology, histochemical characteristics and /or ultrastructure [1, 2, 7, 9, 19, 25, 27, 30, 31, 39, 48, 55]. However, the most pertinent classification system used at present is still descriptive and incorporates different classification schemes [48]. It distinguishes among six fiber types in EOM according to (i) their location in the global (GL) or orbital layer (OL), (ii) type of innervation (i.e. singly (SIF) and multiply (MIF) innervated fibers) [35], (iii) the staining for the myofibrillar adenosintriphosphatase (mATPase) reaction after preincubation in acid and alkaline medium (slow or type I and fast or type II fibers), and (iv) metabolic profile (oxidative, oxidative-glycolytic, glycolytic). Still, this scheme remains limited in recognizing the full extent of the muscle fiber heterogeneity in EOM, not considering the myosin heavy chain (MyHC) isoform composition, as suggested by McLoon and co-workers [28].

In fact, MyHC isoforms are the ones that determine the activity of mATPase and the shortening velocity of myofibers. In large human and rat skeletal muscles four fiber types (I, IIc, IIa, IIb in rat and I, IIc, IIa, IIx in humans) can be distinguished with the histochemical reaction for mATPase after preincubation in alkaline and acid media. Each fiber type expresses corresponding MyHC isoform, except type IIc fibers, which co-express MyHC-1 and $-2 \mathrm{a}[12,35]$. However, in rat, an additional fast MyHC, i.e., IIx or IId (henceforth $-2 \mathrm{x}$ ) can be distinguished immunohistochemically $[4,42]$.

In spite of all the complex research, the classification of muscle fiber types in EOM is still not fully clarified, and neither is the correlation between its structure and function. The studies that considered the MyHC composition of the rat or human EOM $[4,6,8,13,19,20,23,34,40,41,51,55$, 56] applied different methods and therefore the results are mostly not comparable. The reported expression of MyHC isoforms in EOM is not consistent although it is generally agreed that EOM express all the MyHC isoforms present in other striated muscles. Besides these common MyHC isoforms, the EOM-specific extraocular (MyHC-eom), $\alpha$ cardiac (MyHC- $\alpha$ ) and developmental MyHC isoforms, i.e., MyHC-embryonic (-emb) and -neonatal (-neo) are expressed in EOM as well.

The parallel data on serial histo- and immunohistochemical EOM profiles of MyHC isoforms in rat and human EOM have been scarce so far. In this study, we applied the above-mentioned methods and in case of human EOM in situ hybridization as well to obtain an additional insight into the fiber type characteristics and MyHC isoform expression in normal rat and human ocular medial rectus muscles (MR). The purpose of this study was also to determine whether the rat EOM could serve as a model for human EOM structure in experiment and disease, despite rat's less complex visuomotor repertoire.

\section{Methods}

Materials

In this study, ten whole ocular medial rectus (MR) muscles of 2 to 3-month old female Wistar rats with $220-250 \mathrm{~g}$ body weight and ten human post-mortem MR muscles were studied. The human EOM were obtained within $12 \mathrm{~h}$ after sudden death of presumably healthy males (22 to 56 years of age). The study was designed in compliance with Helsinki ethical requirements and approved by the state ethical committee. The rats were painlessly exsanguinated under ether anesthesia. The whole muscle samples were immediately frozen in liquid nitrogen and cut into $10-\mu \mathrm{m}$-thick cross sections.

\section{Histochemistry}

Both human and rat MR muscle sections were processed for histochemical demonstration of the mATPase activity after preincubation at $\mathrm{pH} 4.4$ and 9.4 [14, 32], for succinate dehydrogenase (SDH) [38] and glycerol-3-phosphate dehydrogenase activity ( $\alpha$-GPDH) [22].

\section{Immunohistochemistry}

MyHC isoforms in individual muscle fibers were demonstrated by monoclonal antibodies directed against various MyHC isoforms of rat: BA-D5 (MyHC-1 or $\beta$-slow), SC71 (MyHC-2a), BF-35 (MyHC-2x by exclusion), BF-F3 (MyHC-2b) [42]. Two commercially available antibodies specific to developmental (MyHC-emb) and neonatal (MyHC-neo) MyHC isoforms (Novocastra) were also used. In some of the rat and human muscle samples, additional antibodies were applied: MYH6 specific to MyHC- $\alpha$ (Sigma Prestige Antibodies), 6H1, specific to MyHC-2x of various species, 10F5, specific to MyHC-2b (applied only in human samples), and 4A6, specific to MyHC-eom. The last three antibodies were purchased by Developmental Studies Hybridoma Bank at the University of Iowa [24, 47]. The appropriate dilutions of primary antibodies (in phosphate buffered saline with the addition of $0.3-0.5 \%$ normal bovine serum) were established. The peroxidase-conjugated 
rabbit anti-mouse IgG (Dakopatts, Denmark) was used as the secondary antibody. To reveal the binding of antibodies, diaminobenzidine tetrahydrochloride (DAB, 0.05\%) dissolved in $0.2 \mathrm{M}$ acetate buffer, $\mathrm{pH} 5.2$ with $0.01 \%$ hydrogen peroxide) or 4-chloro-1-naphthol (C1N, 0.05\%, dissolved in $50 \mathrm{mM}$ TRIS-HCl buffer, $\mathrm{pH}$ 7.4-7.6) were used as chromogens. The control sections were incubated without the primary antibody.

In situ hybridization

Serial cryosections of human ocular MR muscles were processed for in situ hybridization with probes, specific to mRNA transcripts of 1 or $\beta$-slow, 2a, 2x, 2b, embryonic and neonatal MyHC genes [44]. The riboprobes were prepared with digoxigenin-labeled UTP according to the guidelines of the manufacturer (Roche Molecular Biochemicals). In situ hybridization procedure was adapted from Horton and co-workers [17] with minor modifications [47].

\section{Fiber typing}

For fiber typing, at least 2,000-2,500 fibers per muscle were sampled. The data were collected independently and separately for every section and layer, and each fiber type. From each histochemically stained muscle section and each section processed for $\mathrm{MyHC}$ isoform detection photos were taken or images were captured by the video camera. Identical fibers were marked on successive serial sections. Further, their staining pattern with mATPase, SDH, $\alpha-$ GPDH and the expression of different MyHC isoforms were compared to determine the previously described six main fiber types [51].

\section{Results}

Arrangement of muscle fibers into layers

In human and rat ocular MR muscles, the fibers were arranged mainly into two layers: the peripheral orbital layer (OL), and the internal global layer (GL). The layers were more distinct in rat, in which the OL was narrow, it consisted of smaller muscle fibers (mostly with diameter less than $20 \mu \mathrm{m})$. The GL was wider and constituted the predominating muscle portion with larger muscle fibers (diameters mostly from 20 to $40 \mu \mathrm{m}$ ). In humans, however, such a distinct separation into layers was not that obvious, because of more gradual muscle fiber type transition from the OL over larger intermediate zone to the GL. There was also a more extensive layer of perimysium surrounding human MR muscle bundles compared to rat MR muscle bundles (Fig. 1a, b). Though larger human ocular MR muscles, the diameters of human and rat muscle fibers did not differ very much (human fiber diameter range 7.1$40.3 \mu \mathrm{m}$ vs. rat $10.6-38.4 \mu \mathrm{m}$ in the GL and human 3.4$26.6 \mu \mathrm{m}$ vs. rat 5.5-23.4 $\mu \mathrm{m}$ in the OL) (Fig. 1a, b).

Muscle fiber types determined according to the mATPase reaction and metabolic profile

Muscle fibers of very similar characteristics could be found in both human and rat muscles. Serial profiles of EOM fibers from the midbelly muscle region across different histochemical reactions are shown in Fig. 2 and Table 1.

At least four fiber types in the GL and two in the OL could be distinguished in both species according to the reaction for mATPase and the fiber metabolic profile as well. Two main categories, i.e., slow or type I fibers and fast or type II fibers could be distinguished. Type I fibers were lightly stained after alkaline preincubation and darkly after the acid preincubation. The fibers with the opposite staining characteristics were classified as fast or type II fibers. Further sub-grouping of fast fibers was achieved according to their metabolic profile revealed by the reaction for SDH and $\alpha-\mathrm{GPDH}$ into three subtypes: oxidative, glycolytic, and oxidative-glycolytic.

In the GL of both species, the muscle fibers were arranged in a rosette-like pattern, where each rosette was composed of a central slow or type I fiber, surrounded by at least all three, the above-mentioned subtypes of fast or type II fibers (Fig. 2). The slow or type I fibers displayed rather low oxidative and glycolytic activity (Fig. 2).

In the OL, where in both species oxidative fast fibers predominated over less oxidative slow fibers (70-97\% vs. $3-30 \%$ ), the oxidative capacity of all fibers was generally higher and the glycolytic one lower than those of fibers in the GL (Figs. 1a, b and 2).

In the GL of the human MR midbelly only, the share of slow or type I fibers was higher than that in the rat MR muscles (10-30\% vs. 10\%). In general, the human MR muscle fibers were also more oxidative than the rat muscle fibers. An additional difference among the muscles of both species pertains to the connective tissue separating the muscle fascicles, which was in the human MR more extensive than in the rat MR muscle (Figs. 1a, b, 2 and 3).

\section{Expression of $\mathrm{MyHC}$ isoforms and transcripts}

In both layers of both species, slow or type I fibers, classified according to mATPase reaction, expressed MyHC-1 as they were labeled by BA-D5 antibody. These fibers were also labeled by BF-35 antibody, which recognizes all MyHC isoforms, except $-2 x$. Most of type I fibers were unlabeled by SC-71, specific to MyHC-2a of rat (Figs. 3 and 6). In human skeletal muscles, type I fibers 
Fig. 1 Cross section of a human and $\mathbf{b}$ rat ocular medial rectus muscle. Histochemical staining for succinate dehydrogenase (SDH) exhibits higher oxidative activity in the thinner orbital layer than in the thicker global layer. Human MR muscle is much larger with a broad intermediate layer and a lot of connective tissue separating muscle fascicles. Scale bar $50 \mu \mathrm{m}$

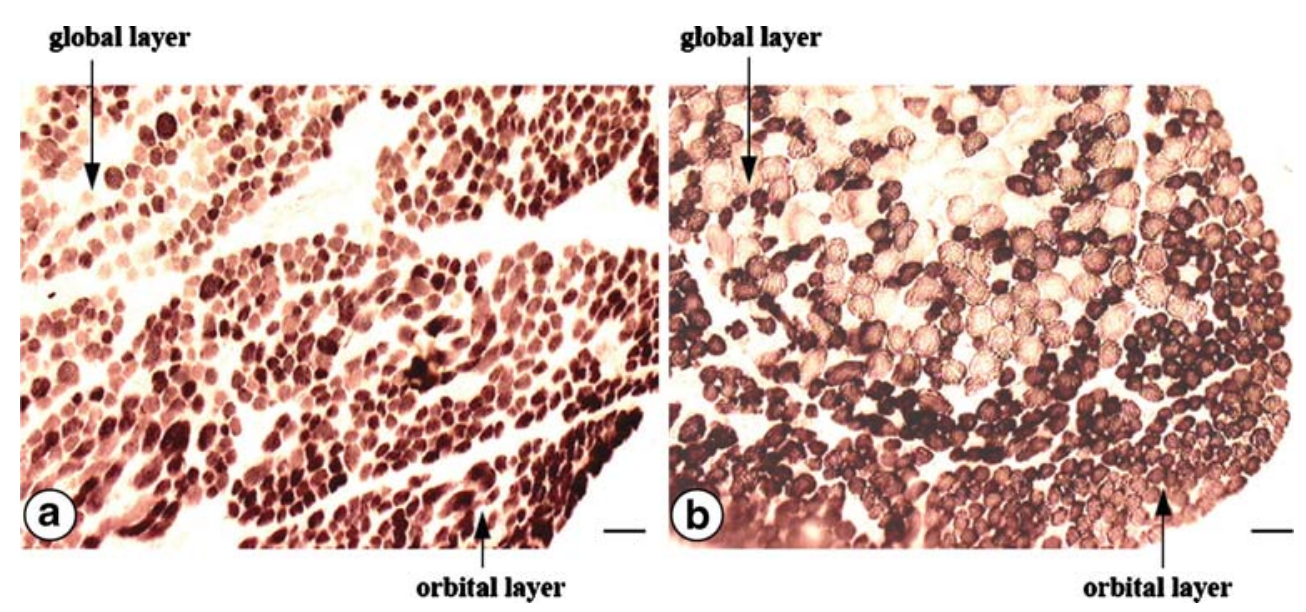

were slightly labeled with BF-F3 specific to MyHC-2b of rat. Two other antibodies, $6 \mathrm{H} 1$ and $10 \mathrm{~F} 5$, specific to MyHC-2x and $-2 b$ of various species, to our knowledge for the first time applied in EOM in this study, also labeled most of type I or BA-D5 positive fibers, $6 \mathrm{H} 1$ only weakly, but 10F5 intensively (Fig. 4). But type I fibers of rat were not labeled by these three antibodies (not shown). Most of type I fibers of both species in both layers were recognized by the antibody specific to MyHC- $\alpha$, (Table 1 , see also the results of our previous study [51]).

In the GL and OL of human MR muscle the fast or type II fibers were labeled by the antibodies specific to rat MyHC-2a (SC-71), -2x (BF-35, stains all MyHC except $-2 x$, not shown, see our previous study [51]), and weakly with the antibody BF-F3, against rat MyHC-2b (Fig. 3). The other antibody specific to MyHC-2x, 6H1, also labeled all human type II fibers (Fig. 4). Contrary to BF-F3, the 10F5 antibody, specific to MyHC-2b as well, stained only some type II fibers (Fig. 4). Some of the type II fibers were stained with the antibody 4A6, specific to MyHC-eom (Fig. 5), and rarely with the antibodies directed against MyHC-emb and -neo isoforms as well (not shown), the latter being expressed only in few type II fibers.

In the rat GL, some type II fibers of smaller diameter expressed MyHC-2a as they were stained by SC-71 antibody. Most of them obviously co-expressed variable proportion of $\mathrm{MyHC}-2 \mathrm{~b}$ and $\mathrm{MyHC}$-eom, as they were moderately labeled by BF-F3 and by 4 A6 antibody as well (Fig. 5). The type II fibers with larger diameter were either unlabeled by BF-35 and stained by $6 \mathrm{H} 1$ (Fig. 6) or stained to variable extent by 4A6 antibody (Fig. 5a), indicating that they expressed either MyHC-2x or co-expressed MyHC-2x and -eom. The rest of type II fibers, located mainly at the outer border of a fascicle, were intensively stained by BFF3 antibody, thus assumed to express only MyHC-2b. There was no expression of MyHC-emb and -neo isoforms within muscle fibers in the GL (not shown).

In some fascicles of the OL of rat almost all type II and type I fibers were stained by 4A6 antibody (MyHC-eom),
(Fig. 5). The antibody against MyHC- $\alpha$ labeled many type II fibers as well. Similarly, there was uneven distribution of fibers expressing MyHC-2a (SC-71 positive) and -2x (BF35 negative, $6 \mathrm{H} 1$ positive), for the latter two see Fig. 6. Actually, there were fascicles with fibers expressing MyHC-eom (Fig. 5), $-2 a,-2 x$ and $-2 b$, and fascicles with fibers expressing MyHC-emb isoform (not shown). The MyHC-neo isoform was either not expressed or present only in scarce fibers of rat OL (Fig. 5).

As demonstrated by in situ hybridization technique, in human type I fibers the corresponding 1 or $\beta$-slow MyHC transcripts were predominantly expressed, but they seemed to be expressed in some type II fibers as well. Similarly, 2a MyHC transcripts were abundantly expressed in many type II fibers, whereas $2 \mathrm{x}$ and $2 \mathrm{~b}$ MyHC transcripts were revealed only in a minor population of type II fibers. The embryonic and neonatal MyHC transcripts were present only in few fibers, the neonatal ones being much scarcer than the former ones. Comparing the expression of $\mathrm{MyHC}$ transcripts with immunohistochemical profile no clear correlation could be found (Fig. 4).

\section{Discussion}

In this study we have proved that almost identical muscle fiber types exist in rat and human extraocular muscles. The majority of fibers are hybrid fibers, co-expressing two or more MyHC isoforms. To our knowledge in this study the expression of $\mathrm{MyHC}-2 \mathrm{~b}$ isoform and $\mathrm{MyHC}$ gene transcripts in human EOM muscle has been demonstrated for the first time. Furthermore, to our knowledge this is the first study in which the distribution of MyHC isoforms in the extraocular muscle fibers of different species was compared.

We confirmed that muscle fibers of human and rat MR muscle are organized into a thicker GL and a thinner OL [33]. Previously described marginal zone (MZ) adjacent to the OL was more evident in human than in rat ocular MR muscles, however it was thin and was to our observation 


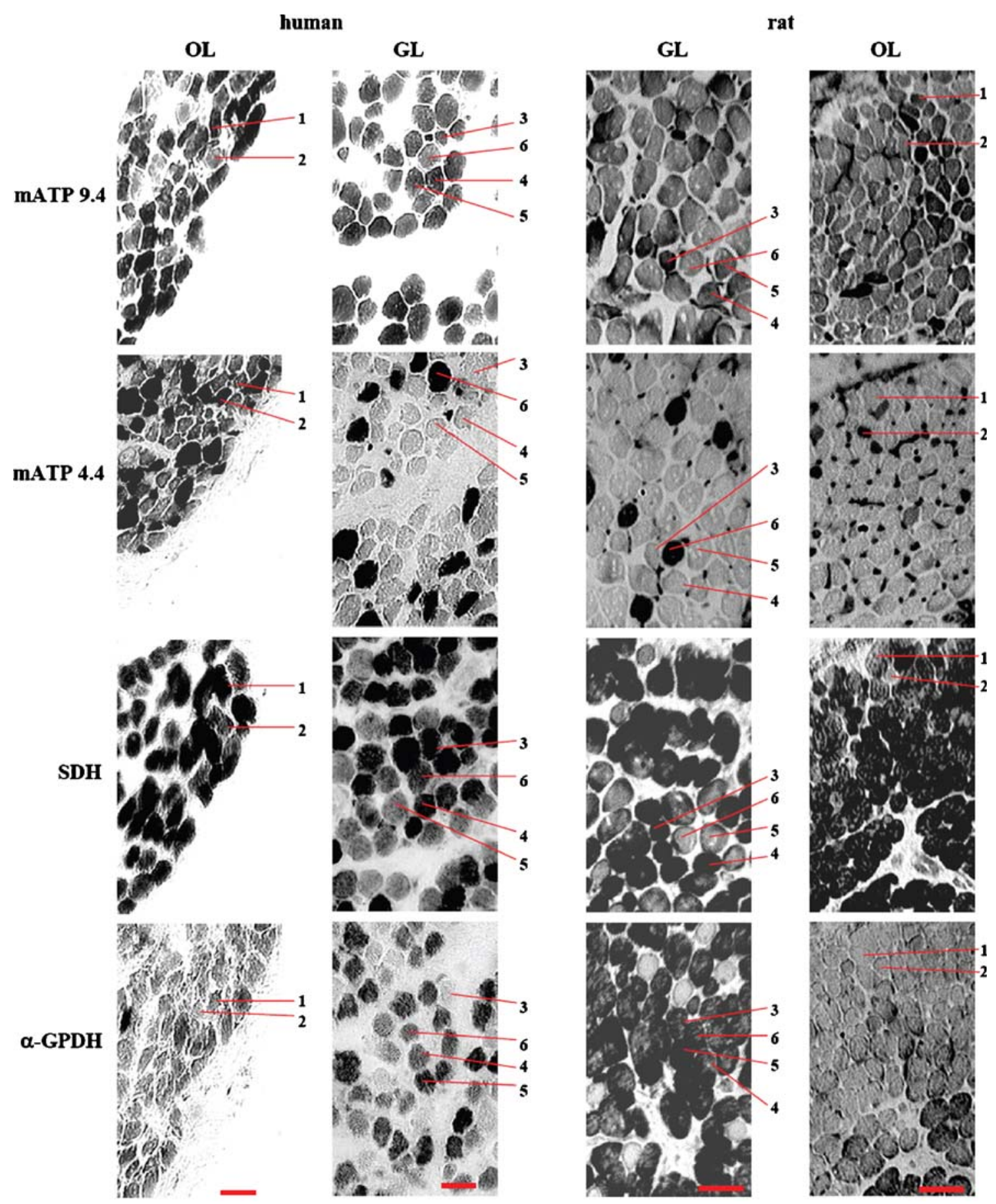

Fig. 2 Histochemical staining of serial cross sections from the orbital $(O L)$ and global layer $(G L)$ of human (left column) and rat (right column) ocular medial rectus muscle, assayed for mATPase after preincubation at $\mathrm{pH} 9.4$ (fibers number 1 are fast fibers, stained dark), (slow fibers are number 2, light fibers), mATPase after preincubation at $\mathrm{pH} 4.4$ (number 1 fibers are light, slow fibers are dark, number 2), $\alpha$ GPDH and SDH. Four different fiber types are indicated in the global muscle layer (slow numbered as 6 , fast oxidative numbered as 3 , fast oxidative- glycolytic as 4 , fast glycolytic numbered as 5). Scale bar $50 \mu \mathrm{m}$ similar to the fibers positioned between the $\mathrm{OL}$ and the GL [55].

As previously found in rat $[48,49]$, the muscle fibers of larger diameter (from 20 to $40 \mu \mathrm{m}$ ) with various metabolic activity were present in the GL, while in the OL smaller, (less than $20 \mu \mathrm{m}$ ), mostly highly oxidative muscle fibers were found in both species. The human MR muscles were larger due to the higher absolute number of muscle fibers, while the muscle fiber diameters were within the range of rat muscle fiber diameters. Interestingly, the muscle fibers 
Table 1 Histochemical and immunohistochemical characteristics of human and rat ocular medial rectus muscle fibers

\begin{tabular}{|c|c|c|c|c|c|c|c|c|}
\hline \multirow[t]{2}{*}{ Fiber type } & \multicolumn{4}{|l|}{ MyHC isoform } & \multicolumn{2}{|c|}{ mATPase (pH) } & \multirow{2}{*}{$\begin{array}{l}\text { SDH } \\
\text { Huma }\end{array}$} & \multirow{2}{*}{$\begin{array}{l}\alpha \mathrm{GPDH} \\
\text { d rat }\end{array}$} \\
\hline & Human & $\%$ & Rat & $\%$ & 9.4 & 4.4 & & \\
\hline \multicolumn{9}{|l|}{ Orbital layer } \\
\hline $1 \mathrm{SIF} \#$ & $\mathrm{a}, \mathrm{x}, \mathrm{b}, \mathrm{eom},(\mathrm{emb}, \mathrm{neo}) *$ & $70-97$ & $\mathrm{a}, \mathrm{x}, \mathrm{b}, \mathrm{eom},(\mathrm{emb}, \mathrm{neo})^{*}$ & $70-97$ & + & - & +++ & \pm \\
\hline $2 \mathrm{MIF} \#$ & $\mathrm{I}, \mathrm{a}, \mathrm{x}, \mathrm{b}, \mathrm{eom},(\mathrm{emb}, \mathrm{neo})^{*}$ & $30-3$ & $\mathrm{I}, \mathrm{a}, \mathrm{x}, \mathrm{eom},(\mathrm{emb}, \mathrm{neo})^{*}$ & $30-3$ & - & + & ++ & \pm \\
\hline \multicolumn{9}{|l|}{ Global layer } \\
\hline 3 SIF\# & $\mathrm{a}, \mathrm{x}, \mathrm{eom}$ & $30-25$ & $\mathrm{a}, \mathrm{x}, \mathrm{eom}$ & 30 & + & - & +++ & - \\
\hline 4 SIF\# & $\mathrm{a}, \mathrm{x}, \mathrm{b}, \mathrm{eom}$ & $30-25$ & $\mathrm{a}, \mathrm{x}, \mathrm{b}, \mathrm{eom}$ & 35 & + & - & +++ & ++ \\
\hline 5 SIF\# & $\mathrm{b}, \mathrm{x}, \mathrm{eom}$ & $25-20$ & $\mathrm{~b}, \mathrm{x}, \mathrm{eom}$ & 25 & + & - & \pm & +++ \\
\hline $6 \mathrm{MIF} \#$ & I $(\mathrm{x}, \mathrm{b}, \mathrm{eom}, \text { neo })^{*}$ & $10-30$ & $\mathrm{I},(\mathrm{eom})^{*}$ & 10 & - & + & \pm & \pm \\
\hline
\end{tabular}

$\mathrm{I}=$ MyHC ß/slow, $\alpha$ cardiac, $\mathrm{a}=$ MyHC-2a, $\mathrm{b}=$ MyHC-2b, $\mathrm{x}=$ MyHC-2x, eom = MyHC-extraocular, emb = MyHC-embryonic, neo $=$ MyHCneonatal

* isoforms in brackets are expressed in some fibers only

Enzyme activity: - (none), \pm (very low), + (low), ++ (intermediate), +++ (high)

\# For a better understanding of the existing literature on extraocular muscles, we also add the nomenclature used with classifying fibers according to the type of innervation: $S I F=$ singly innervated fibers, $M I F=$ multiply innervated fibers

of monkey are larger, more variable in size, and fewer than in human EOM (e.g., 8,000-11,800 fibers in monkey vs. 17,700 to 24,500 fibers in humans) $[20,21]$.

In large skeletal muscles, three to four major fiber types can be revealed by mATPase histochemistry [12]. However, in ocular MR muscles the mATPase histochemistry alone was insufficient to completely distinguish fiber subtypes although a variable incubation time in alkaline and acid media had been used within a wide span of $\mathrm{pH}$ values [39, 50, 51].

Nevertheless, following the already described simplified classification system applied so far for EOM fiber types according to which six fiber types can be distinguished regarding to their location, type of innervation [36, 37, 48, 55], the mATPase activity and metabolic profile [37]. Slow fibers determined in this study obviously corresponded to multiply innervated fibers (MIF), while fast fibers corresponded to singly innervated fibers (SIF) described in other studies [37, 48]. In the GL we could identify at least three fast fiber types (labeled as 3,4, and 5), besides one slow or one hybrid slow/ fast fiber type (labeled as 6). Fiber type 3 was, oxidative and thus obviously fatigue resistant, fiber type 5 was glycolytic and must be fatigable, and fiber type 4 was of intermediate oxidative-glycolytic type (Table 1 and Fig. 2). In the OL, additionally, one fast oxidative fiber type (number 1, Table 1, Fig. 2) in both, human and rat MR muscles was identified.

In both species the single slow type fibers in the GL (number 6 in Table 1 and Fig. 2) and OL (number 2, Table 1, Fig. 2) exhibited low oxidative and low glycolytic activity. These were fatigable pure slow or hybrid fibers coexpressing slow MyHC with other fast MyHC isoforms. The functional role of these fibers is not well understood. Since these global slow type fibers, (called also MIF fibers), develop first they probably allow proprioceptive information to be used in visual system development (36). Orbital fast fibers (called also SIF fibers) mature the last and may directly impact the range and precision of eye movements. They contain the largest bunches of mitochondria, which is consistent with the elevated fatigue resistance and a sustained level of eye position maintenance.

To better define the fiber types according to their oxidative capacity, the reaction for SDH was used in the present study, as the activity of the other marker for oxidative metabolism, the nicotineamide adenine dinucleotide dehydrogenase (NADH) is generally very high in EOM and it hardly distinguishes among fiber types, especially in human $\operatorname{EOM}[19,50]$. However, the reported proportions of GL slow fibers in human EOM vary, ranging from 10 to $30 \%$ [55]. Such variability in results is most probably due to the variable length of muscle fibers, extending from the proximal to the distal part of human extraocular muscle [2, 27, 39, 40, 48, 55].

The unique extraocular MyHC isoform (MyHC-eom), considered as a fast one and not detected in limb muscles, is obviously abundantly expressed in EOM [3, 56]. Until recently, its presence could only be proved with SDS polyacrylamide gel electrophoresis (SDS-PAGE). The share of MyHC-eom confirmed in rat EOM homogenates was 25 $\%$ of the total muscle myosin $[3,51]$. In this study, many OL muscle fibers of both species stained positively with the commercially available monoclonal antibody 4A6 against MyHC-eom. On the contrary, the fibers of the GL were labeled less intensively with this antibody (Fig. 5). Therefore we assume that MyHC-eom is co-expressed with other isoforms in many fibers, especially in the OL. Similarly, Rubinstein and Hoh [40] found MyHC-eom in orbital fast fibers in rat EOM as well Kjellgren and co-workers reported that approximately $25 \%$ fibers in GL of other three human 


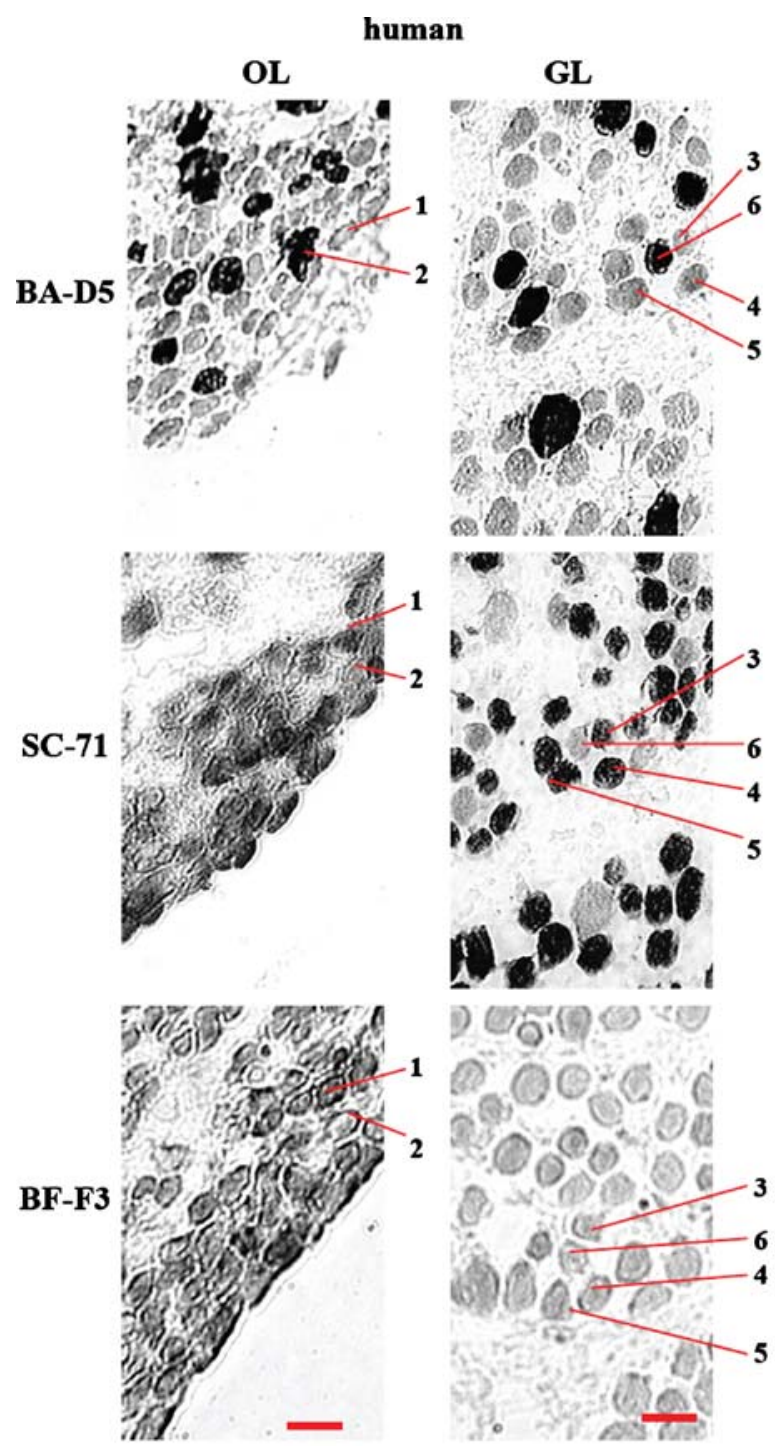

rat

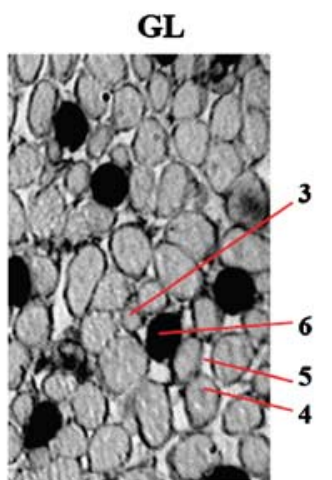

OL
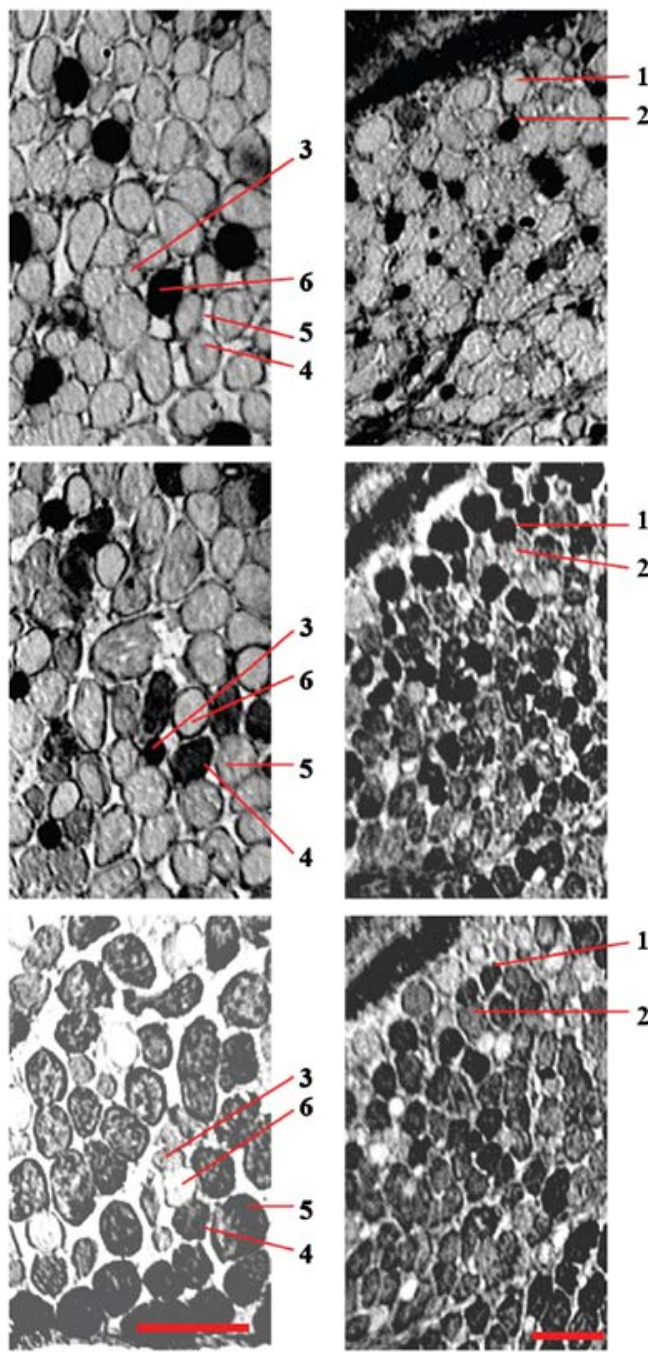

Fig. 3 Immuno-peroxidase staining of serial cross sections from the orbital $(O L)$ and global muscle layer $(G L)$ of human (left column) and rat (right column) medial ocular rectus muscle, assayed for myosin heavy chain isoforms: MyHC-1 ( $\beta$ slow) (BA-D5 as monoclonal

extraocular rectus muscles (the MR was not analyzed), coexpressed MyHC -eom and -2a, but contrary to our findings they found very few MyHC-eom expressing fibers (3\%) in the OL [19]. Further, in the rabbit EOM the MyHC-eom expression was determined in both, the GL and OL [5], while in dog its presence was confirmed only in the OL [5].

The presence of another fast $\mathrm{MyHC}$ isoform, i.e., $-2 \mathrm{x}$, expressed in large skeletal muscles as well, was not clearly confirmed in EOM due to lack of an antibody specific to MyHC-2x and due to similar migration of MyHC-2a and $-2 \mathrm{x}$ isoforms in gels after SDS-PAGE in previous studies [3, 19]. However, applying an antibody specific to MyHC-2x $(6 \mathrm{H} 1)$, in this study we undoubtedly demonstrated that MyHC-2x isoform is abundantly expressed in human EOM fibers and in many rat muscle fibers of both layers. antibody), MyHC-2a (SC-71), MyHC-2b (BF-F3). Two fiber types are indicated in the orbital muscle layer (numbered 1 and 2). Four different fiber types are indicated in the global muscle layer (numbered as 6, and 3, 4, 5). Scale bar $50 \mu \mathrm{m}$

Furthermore, applying monoclonal antibodies BF-F3 in rat and 10F5 in humans we confirmed the presence of MyHC-2b isoform, not only in rat but in human EOM as well. To our knowledge this is the first study in which MyHC-2b isoform has been revealed in any human skeletal muscle, though $2 \mathrm{~b}$ MyHC transcripts were demonstrated in human external abdominal oblique and masseter muscles [17]. It should be stressed that the 10F5 antibody did not label any fiber in large limb muscles (biceps femoris, vastus intermedius, vastus lateralis), but it did in human EOM, indicating that MyHC-2b isoform is expressed in these "specific, very fast contracting" muscles.

Furthermore, the expression of MyHC-2b isoform in human MR was additionally confirmed with undoubtedly revealed expression of MyHC-2b transcripts by in situ 
hybridization technique (Fig. 4). Though the expression of MyHC gene transcripts in human EOM did not correlate well with MyHC isoform expression, it was not completely uninformative as the probe specific for MyHC-2b tran- scripts hybridized in MR, but gave absolutely negative results in the large limb muscles (not shown), placed on the same slide as MR muscles and processed simultaneously for in situ hybridization technique.

Fig. 4 MyHC transcript and isoform expression, respectively, revealed by in situ hybridization and immunohistochemistry in human extraocular medial rectus muscle. In the left column $\beta$ slow (a), 2a (b), 2x (c) and 2b (d) $\mathrm{MyHC}$ transcript expression is presented. In the right column MyHC isoforms are revealed by specific monoclonal antibodies: e. MyHC-1 (BA-D5), f. MyHC$2 \mathrm{a}$ and $-2 \mathrm{x}(\mathrm{SC}-71)$, g. MyHC$2 \mathrm{x}(6 \mathrm{H} 1)$ and h. MyHC-2b (10F5). Note that the MyHC transcript and isoform expression do not correlate. Scale bar $100 \mu \mathrm{m}$

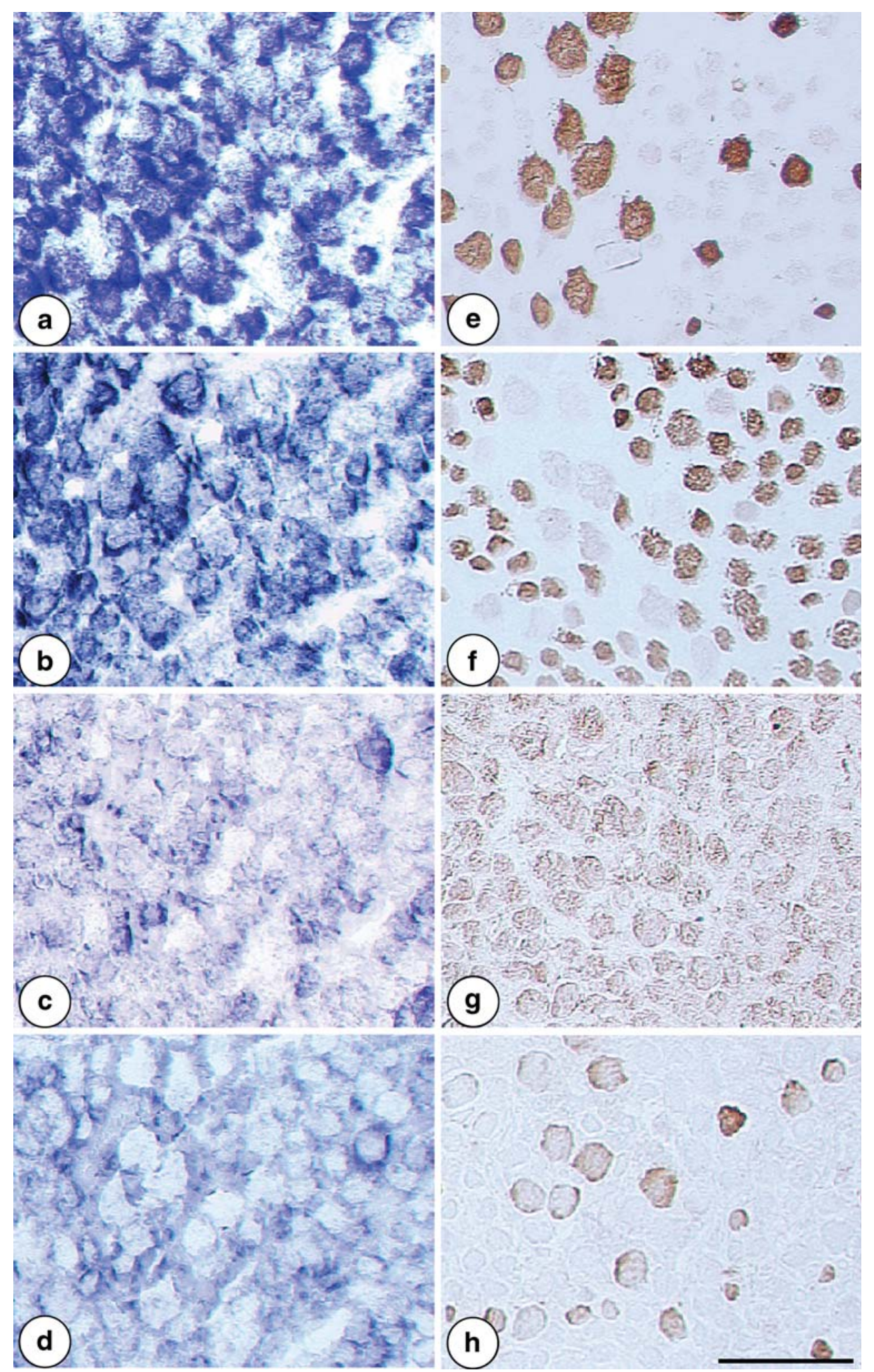


Fig. 5 MyHC-eom expression demonstrated by $4 \mathrm{~A} 6$ antibody in rat (a) and human (b) extraocular medial rectus muscle. Note that the presented rat muscle section is serial to sections presented in Fig. 6, whereas the human one to those shown in Fig. 4. Scale bar $100 \mu \mathrm{m}$
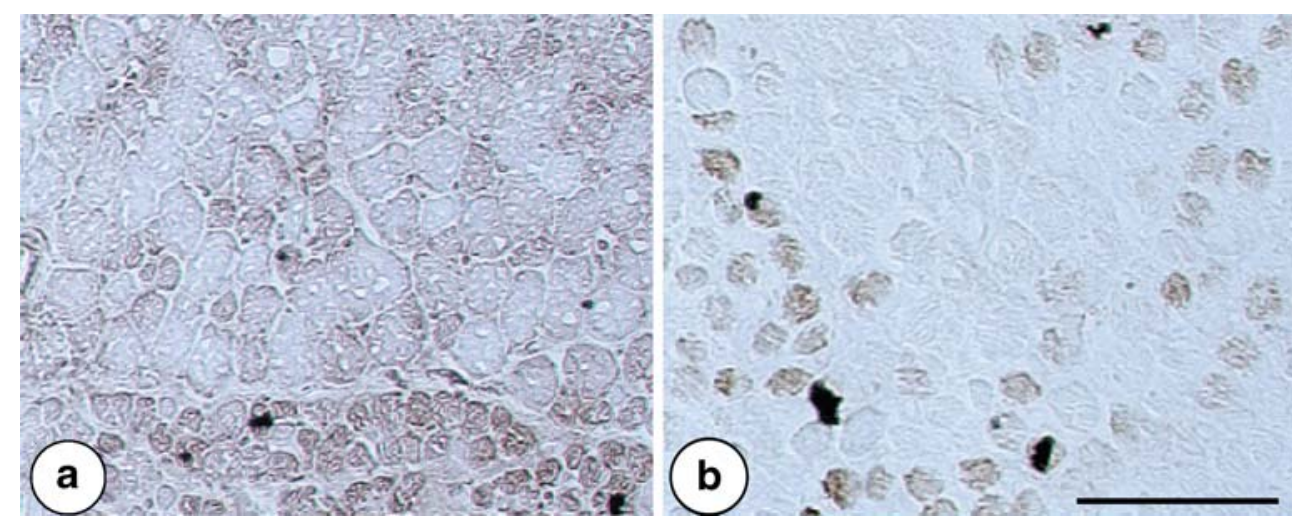

An explanation for such discrepancy in MyHC gene and isoform expression could be a possible posttranscriptional $\mathrm{MyHC}$ gene regulation not only for MyHC-2b but also for other isoforms [15]. Another possibility for so ambiguous results of in situ hybridization technique could also be that the expression of MyHC transcripts in EOM is less abundant than in large skeletal muscles and that the method is not sensitive enough to offer better results, though good results were obtained in large skeletal muscles [47].

Similarly, as found in human EOM, MyHC-2b expression has been detected in bovine EOM but not in trunk and limb muscles [26, 54]. According to previous studies [7, 40, $51,52]$, MyHC-2b is the predominant isoform in the rat EOM global region $(50 \%)$. In dog, the predominance of MyHC-2b isoform (50\%) in the GL of the muscle belly was also found, though like in humans it was not found in large skeletal muscles [46]. In the OL of the belly region MyHCeom predominated $(65-75 \%$ of total $\mathrm{MyHC}$ ) [5]. Evaluating mRNA levels by competitive polymerase chain reaction high expression of MyHC transcripts coding for fast $\mathrm{MyHC}$ isoforms (MyHC-2x 29.9\%, MHC-2a 29.3\%, MyHC-2b $24.5 \%$ ) was also found in the adult rat EOM [23].

Another specificity of EOM muscles is the expression of developmental MyHC isoforms even in adult stage. The presence of MyHC-emb and -neo isoforms predominantly in OL within the midbelly region of adult EOM, reported previously $[34,40,51,53,55]$ and confirmed in this study, seems to be a unique characteristic of the muscles innervated by cranial nerves. However, it was found that the pattern of $\mathrm{MyHC}$ isoform expression may change along the length of rabbit and rat EOM fibers, whereby the majority of fast and developmental MyHC isoforms expressing fibers were present in the middle muscle region of the OL and less in the GL $[18,25,28,41]$.

The characteristic co-expression of two to three MyHC isoforms for EOM has been described in skeletal muscles as well [43, 45, 47, 49, 51], however the co-expression in such a great extent (over $60 \%$ of muscle fibers) is a unique feature of EOM. Moreover, the hybrid fibers are even more numerous in human than in rat MR muscles as found in this study (Table 1, Figs. 3 and 5). However, the large share of hybrid fibers in human EOM could also be ascribed to the non-specificity of antibodies as they were not human specific, while in rat their specificity has been proved [42]. Nevertheless, the EOM fibers obviously exhibit multiple patterns of gene regulation [56], and due to continuous myogenesis triggered by the unique EOM stem cells [29], the individual EOM fibers exhibited co-
Fig. $6 \mathrm{MyHC}-2 \mathrm{x}$ expression demonstrated by BF-35 antibody (a), specific to all $\mathrm{MyHC}$ isoforms except-2x and $6 \mathrm{H} 1$ (b), specific to MyHC-2x in rat extraocular medial rectus muscle. Note the labeled (arrows) MyHC-2x fibers, that are unlabeled by BF35 (a) and moderately stained by $6 \mathrm{H} 1$ (b). Scale bar $100 \mu \mathrm{m}$
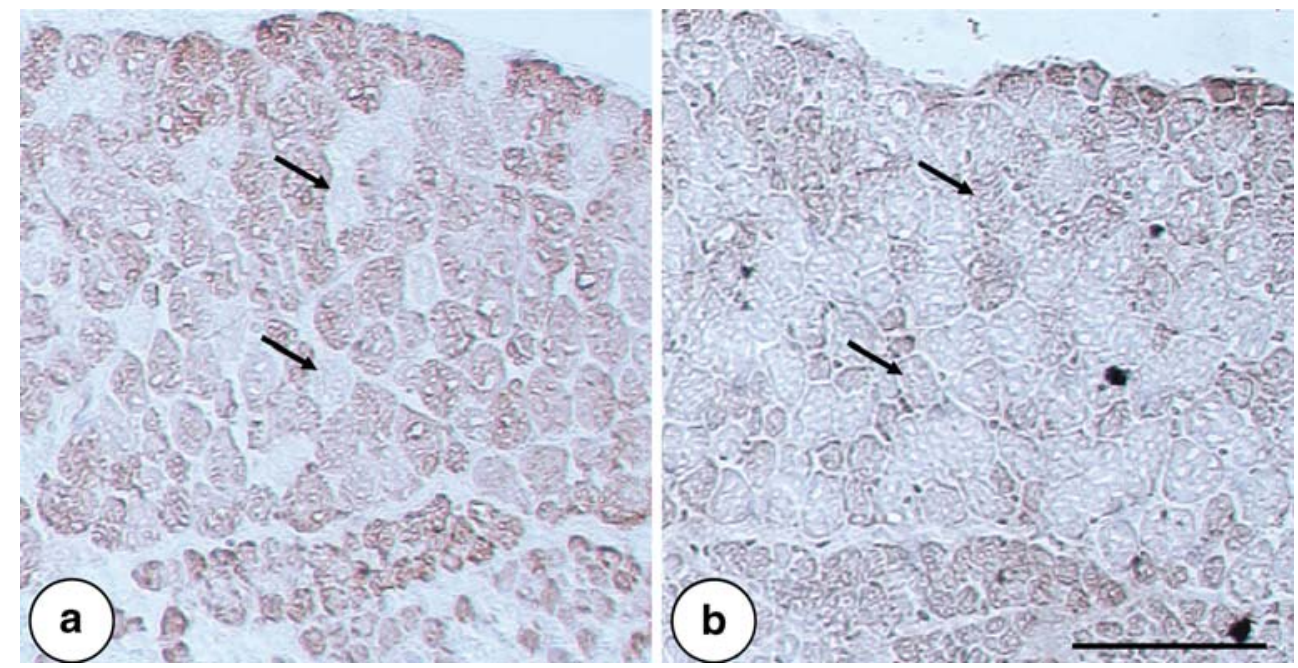
expression of multiple MyHC isoforms in both muscle layers of both species. The epigenetic influences, i.e., a visual maldevelopment, metabolic and neuromuscular diseases, probably essentially contribute to the understanding how the EOM phenotype is established [8, 11, 19, 20, 28].

The comparison of EOM ontogeny in different species confirms that the sequential development of fiber types is conserved in frontal eyed animals but may follow a different sequence in lateral-eyed species. Although different cranial nerves innervate different extraocular muscles the EOM are similar in their function and structure. Actually, no difference in the fiber type composition of all six EOM among cat, rabbit, guinea pig and rat was found [2]. It is also assumed that the EOM fiber types are largely conserved across mammalian species [37].

In conclusion, the neuromuscular junction formation appears to follow similar pathways in rat, monkey, and humans [36]. In the human and rat MR six muscle fibers types can be distinguished that are arranged within two muscle layers and are of similar size, in spite of large difference in body size of the two species [50,51]. However, the muscle bundles in the human MR muscles are larger and more numerous. Due to the more extensive connective tissue that surrounds individual fibers and bundles in human MR muscle, the fiber distribution does not appear as regular as in rat MR muscles. What is the functional consequence of this kind of the muscle arrangement, as well as greater extent of $\mathrm{MyHC}$ isoform co-expression in human than in rat MR, remains unclear and so does the overall understanding of the complex MR muscle physiology and pathophysiology.

Nevertheless, similar structure of human and rat MR muscle and similar characteristics of fiber types justify rat MR muscles to be a suitable model for experimental studies which would lead to better understanding of human MR muscles in experiment or disease.

Acknowledgements The authors would like to thank Mrs. Ana Tomažinčič, Mrs. Majda Črnak Maasarani, Mrs. Andreja Vidmar, Mrs. Nataša Pollak, Mr. Marko Slak, and Mr. Milan Števanec for technical assistance. The Ministry of Education, Science and Sport (Slovenia) supported the research.

Open Access This article is distributed under the terms of the Creative Commons Attribution Noncommercial License which permits any noncommercial use, distribution, and reproduction in any medium, provided the original author(s) and source are credited.

\section{References}

1. Asish CN, Cheng M (1982) Differentiation of fibre types in an extraocular muscle of the rat. J Embryol Exp Morph 71:171-191

2. Asmussen G (1979) Korrelation zwischen strukturellen und funktionellen Paramtern der ausseren Augenmuskelfasern von Saugtieren. In: Drischel H, Kirmse W (eds) Das okulomotorische System. Thieme, Leipzig, pp 156-178
3. Asmussen G, Traub I, Pette D (1993) Electrophoretic analysis of myosin heavy chain isoform patterns in extraocular muscles of the rat. FEBS Lett 335:243-245

4. Bär A, Pette D (1988) Three fast myosin heavy chains in adult rat skeletal muscle. FEBS Lett 235:153-155

5. Bicer S, Reiser PJ (2009) Myosin isoform expression in dog rectus muscles: patterns in global and orbital layers and among single fibers. Invest Ophthalmol Vis Sci 50:157-167

6. Briggs MM, Schachat F (2002) The superfast extraocular myosin (MYH13) is localized to the innervation zone in both the global and the orbital layers of rabbit extraocular muscle. J Exp Biol 205:3133-3142

7. Brueckner JK, Itkis O, Porter JD (1996) Spatial and temporal patterns of myosin heavy chain expression in developing rat extraocular muscle. J Muscle Res Cell Motil 17:297-312

8. Brueckner JK, Porter JD (1998) Visual system maldevelopment disrupts extraocular muscle-specific myosin expression. J Appl Physiol 85:584-592

9. Carry MR, Ringel SP (1989) Structure and histochemisty of human extraocular muscle. Bull Soc Belge Ophthalmol 237:303319

10. Couly GF, Colty PM, Le Douarin NM (1992) The developmental fate of the cephalic mesoderm in quail chick chimera. Development 114:1-15

11. Cheng G, Ap M, Gong B, Leahy P, Khanna S, Porter JD (2004) Conserved and muscle group specific gene expression patterns shape postnatal development of the novel extraocular muscle phenotype. Physiol Genomics 18:184-195

12. Dubowitz V, Brooke MH (1985) Muscle biopsy-a practical approach. 2nd edn. Bailliere Tindall, London, pp 1-475

13. Fujii Y, Abe J, Nonomura S, Moriuchi T, Hizawa K (1990) Immunohistochemical study of fiber types in human extraocular muscles. Acta Pathol Jpn 40:808-814

14. Guth L, Samaha FJ (1970) Procedure for the histochemical demonstration of actomyosin ATPase. Exp Neurol 28:365-367

15. Haddad F, Bodell PW, Quin AX, Giger JM, Baldwin KM (2003) Role of antisense RNA in coordinating cardiac myosin heavy chain gene switching. J Biol Chem 278:37132-37138

16. Harker DW (1972) The structure and innervation of sheep superior rectus and levator palpebrae extraocular muscles. Invest Ophthalmol Vis Sci 11:956-969

17. Horton MJ, Brandon CA, Morris TJ, Braun TW, Yaw KM, Sciote JJ (2001) Abundant expression of myosin heavy chain IIB RNA in a subset of human masseter muscle fibers. Arch Oral Biol 57:1039-1050

18. Jacoby J, Ko K, Weiss C, Rushbrook JI (1990) Systematic variation in myosin expression along extraocular muscle fibres of the adult rat. J Muscle Res Cell Motil 11:25-40

19. Kjellgren D, Thornell LE, Andersen J, Pedrosa Demellöf F (2003) Myosin heavy chain isoforms in human extraocular muscles. Invest Ophthalmol Vis Sci 44:1419-1425

20. Kjellgren D, Stal P, Larsson L, Furst D, Pedrosa Demellöf F (2006) Uncoordinated expression of myosin heavy chain and myosin-binding protein $\mathrm{C}$ isoforms in human extraouclar muscles. Invest Ophthalmol Vis Sci 47:4188-4193

21. Kono R, Poukens V, Demer JL (2005) Superior oblique muscle layers in monkeys and humans. Invest Ophthalmol Vis Sci 46:2790-2799

22. Kugler P (1991) Microphotometric determination of enzymes in brain section. Histochemistry 95:579-583

23. Lim SJ, Jung HH, Cho YA (2006) Postnatal development of myosin heavy chain isoforms in rat extraocular muscles. Mol Vis 12:243-250

24. Lucas CA, Kang LHD, Hoh JFY (2000) monospecific antibodies against the three mammalian fast limb myosin heavy chains. Biochem Biophys Res Commun 272:303-308 
25. Lucas CA, Hoh JF (2003) Distribution of developmental myosin heavy chains in adult rabbit extraocular muscle: identification of a novel embryonic isoform absent in fetal limb. Invest Ophthalmol Vis Sci 44:2450-2456

26. Maccatrozzo L, Patruno M, Toniolo L, Reggiani C, Mascarello F (2004) Myosin heavy chain 2B isoform is expressed in specialized eye muscles but not in trunk and limb muscles of cattle. Eur J Histochem 48:357-366

27. Mayr R (1971) Structure and distribution of fiber types in the external eye muscles of the rat. Tissue Cell 3:433-462

28. McLoon LK, Rios L, Wirtschafter JD (1999) Complex threedimensional patterns of myosin isoform expression: differences between and within specific extraocular muscles. J Muslec Res Cell Motil 20:771-783

29. Pacheco Pinedo EC, Budak MT, Zeiger U, Jorgensen LH, Bogdanovich S, Schroeder HD, Rubinstein NA, Khurana TS (2008) Transcriptional and functional differences in stem cell populations isolated from extraocular and limb muscles. Physiol Genom 37(1):35-42

30. Pachter BR (1982) Fiber composition of the superior rectus extraocular muscle of the Rhesus monkey. J Morphol 174:237-250

31. Pachter BR (1984) Rat extraouclar muscle III. Histochemical variability along the length of multiply innervated fibbers of the orbital surface layer. Histochemistry 80:535-538

32. Padykula HA, Herman E (1955) The specificity of the histochemical method for adenosine triphosphatase. J Histochem Cytochem 3:170-195

33. Peachy L (1971) The structure of the extraocular muscle fibers in mammals. In: Bachy-Rita P, Collins CC, Hyde JE (eds) The control of eye movements. Academic Press, New York, pp 47-66

34. Pedrosa Domellöf F, Holmgren Y, Lucas A, Hoh JF, Thornell LE (2000) Human extraocular muscles: unique pattern of myosin heavy chain expression during myotube formation. Invest Ophthalmol Vis Sci 41:1608-1616

35. Pette D, Staron RS (1990) Cellular and molecular diversities of mammalian skeletal muscle fibbers. Rev Physiol Biochem Pharmacol 116:2-47

36. Porter JD, Baker RS (1992) Prenatal morphogenesis of primate extraocular muscle: neuromuscular junction formation and fiber type differentiation. Invest Ophthalmol Vis Sci 33:657-670

37. Porter JD, Baker RS, Ragusa RJ, Brueckner JK (1995) Extraocular muscles: basic and clinical aspects of structure and function. Major review. Surv Ophthalmol 39:451-484

38. Reichmann H, Pette D (1991) Glycerophosphate oxidase succinate dehydrogenase activities in IIa and Iib fibbers of mouse and rabbit tibialis anterior muscles. Histochemistry 95:429-433

39. Ringel SP, Wilson WB, Barden MT, Kaiser KK (1978) Histochemistry of human extraocular muscle. Arch Ophthalmol 96:1067-1072

40. Rubinstein NA, Hoh JFY (2000) The distribution of myosin heavy chain isoforms among rat extraocular muscle fiber types. Invest Ophthalmol Vis Sci 41:3391-3398

41. Rubinstein NA, Porter JD, Hoh JFY (2004) The development of longitudinal variation of myosin isoforms in the orbital fibers of extraocular muscles of rats. Invest Ophthalmol Vis Sci 45:30673072
42. Schiaffino S, Saggin L, Viel A, Ausoni S, Sartore S, Gorza L (1986) Muscle fiber types identified by monoclonal antibodies to myosin heavy chains. In: Benzi G, Packer L, Siliprandi N (eds) Biochemical aspects of physical exercise. Amsterdam, Elsevier, pp 27-34

43. Schiaffino S, Gorza L, Ausoni S, Bottinelli R, Reggiani C, Larson L, Edstrom L, Gunderson K, Lømo T (1990) Muscle fiber types expressing different myosin heavy chain isoforms. In: Pette D (ed) The dynamic state of muscle fibers. Walter de Gruyter \& Co., BerlinNew York, pp 329-341

44. Smerdu V, Karsch Mizrachi I, Campione M, Leinwand L, Schiaffino S (1994) Type IIx myosin heavy chain transcripts are expressed in IIb fibers of human skeletal muscle. Am J Physiol 267:C 1723-B

45. Smerdu V, Eržen I (2001) Dynamic nature of fibre type specific expression of myosin heavy chain transcripts in 14 different human skeletal muscles. J Muscle Res Cell Motil 22:647-655

46. Smerdu V, Štrbenc M, Meznarič-Petruša M, Fazarinc G (2005) Identification of myosin heavy chain I, IIa and IIx in canine skeletal muscles by an electrophoretic and immunoblotting study. Cells Tissues Organs 180:106-116

47. Smerdu V, Soukup T (2008) Demonstration of myosin heavy chain isoforms in rat and humans: the specificity of seven available monoclonal antibodies used in immunohistochemical and immunoblotting methods. Eur J Histochem 52:179-190

48. Spencer RF, Porter JD (1988) Structural organization of the extraocular muscles. In: Büttner-Ennever JA (ed) Reviews in oculomotor research, vol. 2. Elsevier, New York, pp 33-73

49. Staron R, Pette D (1993) The continuum of pure and hybrid myosin heavy chain-based fibre types in rat skeletal muscle. Histochemistry 100:149-153

50. Stirn Kranjc B, Vončina D (1992) Typisierung der horizontalena ausseren menschlichen Augenmuskeln. Spektrum Augenheilk $6: 114-118$

51. Stirn Kranjc B, Sketelj J, D’Albis A, Ambrož M, Eržen I (2000) Fibre types and myosin heavy chain expression in the ocular medial rectus muscle of the adult rat. J Muscle Res Cell Motil 21:753-761

52. Stirn Kranjc B, Sketelj J, D'Albis A, Eržen I (2001) Long-term changes in myosin heavy chain composition after botulinum toxin A injection into rat medial rectus muscle. Invest Ophthalmol Vis Sci 42:3158-3164

53. Thornell LE, Billeter R, Buttler Browne GS, Eriksson PD, Rinquist M, Whalen RG (1984) Development of fiber types in human fetal muscle. J Neurol Sci 66:107-115

54. Toniolo L, Maccatrozzo L, Patruno M, Caliaro F, Mascarello F, Reggiani C (2005) Expression of eight distinct MHC isoforms in bovine striated muscles: evidence for MHC-2B presence only in extraocular muscles. J Exp Biol 208:4243-4253

55. Wasicky R, Ziya Ghazvini F, Blumer R, Lukas JR, Mayr R (2000) Muscle fiber types of human extraocular muscles: a histochemical and immunohistochemical study. Invest Ophthalmol Vis Sci 41:980-989

56. Wieczoreck DF, Periasamy M, Buttler Browne GS, Whalen RG, Nadal Ginard B (1985) Coexpression of multiple myosin heavy chain genes in addition to tissue specific one in extraocular muscle. J Cell Biol 101:618-629 